\title{
A edição de textos do período colonial brasileiro: a busca necessária das fontes
}

Melânia Silva de Aguiar*

* Professora no Programa de Pós-G raduação em Letras da PUC/M inas e T itular de Literatura B rasileira da UFMG. 
Ler os textos do período colonial brasileiro em edições correntes pode significar a incursão numa floresta de equívocos ou de desvios semânticos consideráveis. J á não se falando das questões mal resolvidas relativamente à autoria de várias composições desta fase, a aguardar estudos mais minuciosos das fontes, os textos impressos quase sempre revelam reproduções mal cuidadas de edições antigas, feitas sem o necessário rigor e sem a preocupação da busca dos melhores e mais confiáveis códices.

Curt Lange, o musicólogo uruguaio que desentranhou para a História, dos velhos baús das casas e igrejas mineiras do século XVIII , antigas partituras musicais, em seus depoimentos sobre suas viagens, conta da destinação dada a estas partituras numa das cidadezinhas visitadas: eram um papel excelente para a confecção dos foguetes usados nas festividades eclesiásticas. Fico imaginando quantas ladainhas ou te deum foram pelos ares, estilhaçados, iluminando as noites de $\mathrm{Mi}$ nas e desaparecendo para sempre, testemunhos mudos, agora inúteis, de um passado que " quer bater à nossa porta" , como diria Cecília Meireles, mas tem as mãos atadas. A luz destes estilhaços, nós a podemos imaginar pelo que restou, ratificando a vitalidade cultural de uma época ímpar no período colonial.

Se pensarmos em outras extensões da cultura mineira setecentista, podemos deduzir que o patrimônio musical não foi o único afetado, e que muito boa pintura, escultura e peças literárias se perderam para sempre. E os projetos? Pois pode-se pensar - além de na obra pronta, acabada - nos momentos anteriores, os dos projetos e os da criação, propriamente. Quantos esboços, desenhos, rascunhos, anotações marginais desapareceram? Fico pensando num poema de Tomás Antônio Gonzaga, em que ele se descreve pondo no fogo velhas composições de 
sua lavra, dedicadas a amores antigos. O que queimaram de seu os poetas de $\mathrm{Mi}$ nas ou outros por eles? E o que existe debaixo da superfície lisa do que restou impresso e nossos olhos não conseguem alcançcar? O que foi rasurado, apagado, refeito, em nome de uma censura moral, estética, id eológica ou lingüística? A figura destes poetas, acossados por seus demônios pessoais e pelos censores da época, estará sempre presente nos pesadelos do nosso tempo; sua pressa em destruir rastros comprometedores na véspera de sua prisão, o poder do E stado já roçando seus calcanhares, será uma imagem aflitiva, permanente. R esta-nos, no entanto, o consolo de que em nossos dias o presente começca a se voltar para o seu passado de forma mais consistente e produtiva.

A pós-modernidade, afirma Michel Contat, faz-se acompanhar de uma volta do olhar ao passado. Nunca, diz ele, os grandes autores foram tão reverenciados, nunca a crítica erudita se interessou tanto pelos processos da criação ${ }^{1}$. Se isto acontece, for a de dúvida, na França, não é menos verdade no Brasil, onde um grupo cada vez maior de estudiosos volta-se para as fontes do texto, buscando neles as respostas para inúmeras questões que se colocam tanto aos especialistas de literatura, quanto aos de lingüística, história etc. E à medida que as técnicas de abordagem do texto se afinam, ou se sofisticam, abre-se um leque de possibilidades no tratamento das edições. A crítica genética, por exemplo, cuja corrente mais atuante no momento encontra-se na F rança, reúne número significativo de seguidores também no Brasil, criando novas possibilidades de edições, voltadas aqui para tudo o que possa trazer significado à compreensão dos processos de criação. Sendo uma das mais modernas teorias de abordagem do texto, estende seu domínio a outros tipos de produção, como as primeiras versões das partituras musicais, os esboços de artistas plásticos, os rascunhos de ensaios científicos, os préprojetos arquitetônicos, enfim, os avant-textes, usand o a nomemclatura de J eanBellemin-Noël para designar o conjunto de testemunhos da criação, objeto instigante e pouco explorado. Mais antiga que a crítica genética e diferentemente desta, a crítica textual ou ecdótica, cujos métodos se aperfeiçoaram na Alemanha no século passado, objetivando limpar os textos editados dos ruídos e desvios sofridos no processo de impressão, não se interessou pelos rascunhos e, sim, pelas fontes impressas do texto, isto é, as edições princips ou as sacramentadas pelo autor, e pelos manuscritos em sua fase final, quando os havia. Ficaram for a de seu interesse, os outros avant-textes, material precioso para a crítica genética e praticamente inexistente no caso de textos do período colonial brasileiro; nestes casos fica difícil falar-se em edição genética, já que nos damos por felizes quando alcançamos, nos velhos arquivos, material manuscrito, inédito ou não, autógrafo ou 
não. Ainda assim, a lição das primeiras edições e dos manuscritos é quase sempre surpreendente para o editor crítico e revela o quão é importante o minucioso trabalho de levantamento das variantes das versões localizadas, a análise detida da versão mais autêntica ou mais fiel às intenções do autor, a escolha do texto-base, isto é, aquele que vai servir ao editor crítico em sua edição e em referência ao qual será montado o quadro de variantes, o aparato crítico. A idéia de que este é um trabalho definitivo, ou seja, a idéia de uma edição ne vari etur, sem possibilidades de alterações futuras, é uma falácia, e a crença na imortalidade ou atemporalidade das edições algo que não mais se sustenta. Na verdade, desde que assentado sobre manuscritos, o texto é de natureza cinética e Nina Catach, estudiosa da crítica textual e da crítica genética, com um certo exagero, afirma que os bons escritores mereceriam uma nova edição a cada dez anos². É preciso salientar que não só as mudanças no campo da teoria literária modificam o olhar sobre o texto, como ainda as novas técnicas encaminham um tratamento diferenciado do material trabalhado. O resultado será inevitavelmente distinto, a prática confirmando a suposição de que a edição crítica dependerá sempre estreitamente do estado em que se encontram as técnicas com que trabalha. Modernamente, por exemplo, é impensável uma edição crítica sem o auxílio do computador: o exaustivo trabalho de ida e vinda das fontes para o texto, do texto para as referência mitológicas, históricas, lingüísticas, geográficas etc., levando a inúmeras revisões, retificações, reconsiderações, acréscimos, cortes - "trabalho beneditino", como já o classificou alguém, pela dose de paciência que exige - estará infinitamente facilitado pelo computador. Entretanto, modernos programas da informática e recursos como o scanner e outros semelhantes jamais conseguirão superar o entendimento que se estabelece entre os dois seres pensantes envolvidos no processo de uma edição crítica: o autor e seu editor crítico. E ntendamos: dois seres pensantes se não se envolvem aí outras figuras como as dos revisores ou copistas que resolvem dar uma ajuda ao escritor e mudam, voluntariamente ou não, o texto original.

É oportuno lembrar aqui o estatuto do manuscrito no período colonial. Circulando entre leitores, embora restritos, do tempo, era de natureza pública, como o são hoje as obras impressas. Diferentemente do manuscrito moderno, de natureza particular, geralmente de propriedade do escritor ou da família, os manuscritos antigos eram reproduzidos por copistas, para este fim contratados, ou por indivíduos interessados em ter ou repassar a obra a outros. Pode-se imaginar a proliferação de erros na reprodução das obras, seja por uma leitura incorreta, seja até mesmo por uma ajuda dada ao texto, na decifração de passagens menos claras, no desdobramento de abreviaturas etc. 
Examinando a edição da poesia de Cláudio Manuel da Costa de 1903, feita por J oão R ibeiro, onde o crítico pretendeu estampar a obra considerada até então completa do poeta mineiro, verifica-se uma quantidade de erros evidentes que, num primeiro exame, não se sabe se partem dos textos originais, do descuido da transcrição impressa ou da fantasia do editor. Estes erros, trnasmitidos de uma a outra edição, mecanicamente, estavam a reclamar há muito o exame minucioso das fontes. Tendo iniciado em 1993, com um grupo de jovens professores e alunos, a execução de um projeto objetivando a edição crítica da obra completa de Cláudio Manuel da Costa, surpreendi-me nestes anos com o número de fontes localizadas, o que prova que nem tudo foi pelos ares e que alguma coisa pode ainda ser feita. Além dos vários manuscritos de outras obras ou fragmentos de obras do escritor mineiro, surpreende particularmente a riqueza manuscrita do Vila Rica, de que foram localizados 10 códices. $N$ ão sendo autógrafos, oferecem, apesar disto, um campo vasto de interesse para a compreensão dos erros registrados nas edições do poema, finalizado em 1773 e somente publicado pela primeira vez em 1839 (edição póstuma portanto). Esta edição, ao que tudo indica não se baseou em manuscrito autógrafo, tantos os equívocos registrados, o que possivelmente tenha motivado injustamente a crítica dos historiadores às incorreções históricas de Cláudio; e, ainda que o manuscrito aí utilizado tenha saído da mão do autor, baseou-se a edição em texto evidentemente censurado, provavelmente pelo próprio Autor, como se verá adiante.

U m exemplo claro de aberração histórica presente na edição de J oão R ibeiro e em outras, que o cotejo dos vários manuscritos do Vila Rica esclarece de forma inequívoca, ocorre na nota 4, feita ao poema pelo Autor, Cláudio M anuel da Costa, quando se refere a Pedro Álvares Cabral. Diz a nota: “O B rasil, que foi descoberto por Pedro Martins Cabral em 1501, é repartido em quatorze capitanias [...]" etc. Em um dos manuscritos do poema existente na Biblioteca Nacional do Rio de J aneiro 9c. 19, 1, 23), encontra-se de fato, como descobridor do Brasil " pedro Martins Cabral" (e 1501(?)). Comparando os manuscritos, no entanto, pode-se depreender que o copista, tendo lido mal as letras iniciais da abreviatura Alvz. (de Álvares), copiou Mrz. (de Martins), formando em cadeia uma lição equivocada. $O$ exame das fontes (e quanto mais rico o material a ser examinado, melhor), no caso de obras não autorizad as pelo Autor, como neste caso, oferece lições infinitamente ricas. A edição de J oão R ibeiro parte, pois, da lição incorreta das primeiras edições. No manuscrito de L isboa, oferecido provavelmente pelo próprio poeta ao Conde de Cavaleiros, consta com clareza a abreviatura Álvz., bem como em outros manuscritos.

Dos dez manuscritos por nós reunidos e cotejados do Vila Rica (cinco na Biblioteca Nacional do Rio de janeiro, um no Arquivo Público Mineiro, dois no 
Instituto Histórico e G eográfico B rasileiro, um na B iblioteca de Saite-G énéviève, em paris e um na Biblioteca Nacional de Lisboa), nenhum é autógrafo, saído da mão do autor. As edições do Vila Rica são, como já se viu, póstumas; portanto, não passaram pelo crivo do autor, não tiveram sua licença final para publicação. Ora, as primeiras edições estão eivadas de erros visíveis (mesmo a edição de 1969, organizada por Augusto de Lima J r., que se diz baseada no manuscrito autógrafo, que aliás nunca apareceu, está cheia de falhas). E m compensação, o manuscrito de Lisboa, além de ser um dos mais corretos (e há que se ter cuidado com esta qualificação correto, aqui não sinônimo de caprichado, bem cuidado), apresenta, no Canto V, 84 versos a mais que os outros manuscritos e edições, versos visivelmente do autor, suprimidos depois por razões de censura. Este códice, de ótima aparência além do mais, pertenceu ao Conde de Cavaleiros, de quem o autor era amigo, e nada faz supor nos versos a mais um enxerto de última hora. Seriam antes considerados inconvenientes para a época, o que provavelmente fez com que o autor os eliminasse. O exemplar oferecido ao Conde de Cavaleiros, ou D. R odrigo J osé de M eneses, governador de M inas de 1780 a 1783, ao que parece não foi alcançado pela censura posterior de mãos alheias ou - por que não? - do próprio Poeta; seguindo com seu dono para Portugal, ficou preservado da mutilação prudente e oportuna. Os manuscritos que circularam no Brasil, ou foram exemplares censurados ou foram cópias destes, portanto também incompletos. Como se sabe, o poema Vila Rica, de Cláudio Manuel da Costa, conta a fundação de Minas, berço do Poeta, e os trabalhos e lutas entre os paulistas desbravadores, representantes da autoridade reinol, e os primeiros habitantes da terra, no povoamente que se seguiu às bandeiras e à exploração do território. A ambigüidade ideológica de que se reveste o poema, presente também em outros textos literários do período, assume por vezes tons comprometedores, o que pode ser claramente visto nos versos a mais presentes no manuscrito de $L$ isboa e ausentes nos demais manuscritos e edições. Pondo o autor, na boca de uma dos sediciosos, F rancisco, um discurso inicialmente patético em sua defesa da maldade e da delinqüência, a fala obliquamente escorrega para uma retórica de defesa da liberdade. Veja-se:

\section{[...] Não é novo}

Viver sem leis, e sem domínio um povo;

Nações inteiras têm calcado a terra

Sem adorar a mão que o Cetro aferra;

E tal houve que creu felicidade

Desconhecer inda a J ustiça:

Tem [advertido] a humana inteligência 
Para abraçar sem susto o que é violência:

Que tormento maior a um livre peito

Que a um homem, a um igual viver sujeito?

Aliberdade a todos é comum;

Ninguém tão louco renuncia à sua.

O bserve-se que a defesa da liberdade e o sonho de viver "sem adorar a mão que o Cetro aferra" não constituem anseios ou pensamentos em si condenáveis. $\mathrm{E}$ mesmo "o abraçar a violência", desde que na defesa da liberdade, tem sua razão de ser. Logo, o "vil" e "infame" F rancisco é capaz de insinuar nas dobras de seu discurso o sonho ilustrado, de qualquer modo perigoso para a época. Somente o conhecimento e o exame das fontes do Vila Rica, com o conhecimento do manuscrito de Lisboa, possibilitaria a recuperação destes versos em nova edição. Ganhou o poema e ganhou a História, já que este é um dado a mais no quebra-cabeças constituído pelos muitos enigmas do período colonial.

I vo Castro, no seu ensaio "Estratégia e táctica da transcrição", observa que as grandes definições dadas para uma edição por um escritor consciente devem ser tomadas como margem mínima de risco:

Quanto mais consciente estiver dos gestos que pratica, ou dos raciocínios que desenvolve, menos riscos corre o editor de decidir mal e mais possibilidade tem de optar por um caminho de consenso geral.

Esta decisão, como se pode imaginar, com a reunião e o exame atento do material a ser trabalhado, o conhecimento das tendências do autor e da época, sejam ortográficas, lexicais ou semânticas, demandam tempo.

Estas não são, entretanto, as únicas dificuldades. A definição do texto-base pode ser outro dos problemas que enfrenta um editor crítico. No caso do Vila Rica nossa definição do texto-base teve suas dificuldades e só pôde de fato ser decidida após minucioso exame dos códices e edições existentes, já que a escolha do manuscrito de Lisboa como referência significativa uma substancial alteração do que vinha sendo a recepção do poema. Convencida da autenticidade dos 84 versos inéditos, por razões de estilo, pelo componente comprometedor de seu conteúdo, pelas circunstâncias de sua existência não havia outro caminho: a nova edição corrige de uma vez por todas, segundo espero, uma falha a partir de agora impensável nas futuras edições do poema. A poesia dos inconfidentes, reunindo a obra completa de Cláudio, G onzaga e A lvarenga peixoto, veio esclarecer questões de autoria e aumentar consideravelmente, no caso de Cláudio, após exaustivas 
pesquisas de fontes e registro de variantes realizados por uma operosa equipe ${ }^{3}, 0$ corpus literário conhecido do Poeta.

É , pois, auspicioso o ressurgimento de importantes edições como a das obras poéticas de B asílio da G ama, por I van Teixeira, do poema Concei ção, de Gonzaga, por R onald Polito, das Cartas Chi lenas, por J oaci Furtado, entre outras. A pesquisa de manuscritos inéditos ao lado das edições antigas já esgotadas parece indicar que algo está mudando no tratamento das edições de textos do período setecentista em Minas Gerais. Desta forma vamos construindo os alicerces da nossa memória.

Na preparação da edição de A poesia dos inconfidentes: poesi a completa de Cláudio manuel da Costa, Tomás Antônio Gonzaga e Alvarenga Peixoto (org. Domício Proença Filho; artigos, ensaios e notas de M elânia Silva de Aguiar et al. Rio de J aneiro: Nova Aguilar, 1996), no que se refere à obra de Cláudio Manuel da Costa, contei com a indispensável colaboração da P rofa. Dra. Eliana Scotti M uzzi da UF M G , de bolsistas de A perfeiçoamento e de Iniciação Científica e, ainda, com o apoio do CNPq, CAPES eFAPEMIG. 